\title{
ARGILAS ESPECIAIS: O QUE SÃO, CARACTERIZAÇÃO E PROPRIEDADES
}

\author{
Antonio C. Vieira Coelho* e Pérsio de Souza Santos \\ Departamento de Engenharia Metalúrgica e de Materiais, Escola Politécnica, Universidade de São Paulo, Av. Prof. Luciano \\ Gualberto, Trav. 3, 380, 05508-970 São Paulo - SP, Brasil \\ Helena de Souza Santos \\ Departamento de Física Geral, Instituto de Física, Universidade de São Paulo, CP 66318, 05315-970 São Paulo - SP, Brasil
}

Recebido em 21/10/05; aceito em 27/1/06; publicado na web em 30/8/06

\begin{abstract}
SPECIAL CLAYS : WHAT THEY ARE, CHARACTERIZATION AND PROPERTIES. Special clays are a group of clays different from the large volume of clay mineral products named "Industrial Clays": kaolins, ball clays, refractory clays, bentonites, fuller's earths, common clays. Two groups of special clays exist: rare, as in the case of hectorite and sepiolite and restricted areas, as in the case of white bentonite, halloysite and palygorskite (attapulgite). A review is given of the most important producers of the special clays and their properties in the Western World, as well as a discussion of the occurrence of these types of clays in Brazil.
\end{abstract}

Keywords: special clays; source clays; rare clays.

\section{INTRODUÇÃO}

A expressão "Argilas Especiais" foi introduzida e está correntemente sendo utilizada pela revista inglesa "Industrial Minerals", desde 1985, para designar um grupo de argilas que se distingue das "Argilas Industriais" por serem comercialmente raras, ocorrerem em quantidades grandes em localidades restritas, por serem produtos industriais modificados quimicamente e, por isso, possuírem elevado valor agregado. A maior parte das Argilas Especiais foi desenvolvida comercialmente para produtos novos ou incomuns, ou para aplicações específicas. Esses desenvolvimentos foram baseados nas características especiais da composição química e da estrutura cristalina de alguns argilominerais.

\section{ALGUMAS DEFINIÇÕES: ARGILAS E ARGILOMINERAIS}

É conveniente apresentar preliminarmente algumas definições fundamentais para que se torne mais precisa a descrição das características estruturais em que se baseou o desenvolvimento das Argilas Especiais atualmente existentes.

Mineral é um elemento ou composto químico inorgânico que é normalmente cristalino e que se formou como resultado de um processo geológico; portanto, um mineral tem composição química e propriedades cristalográficas bem definidas². Rocha é um agregado de cristais de um ou mais minerais. O nome de um mineral deve terminar em "ita" e o de uma rocha em "ito", segundo a IMA "International Mineralogical Association". Nomes tradicionais de minerais e de rochas anteriores à nomenclatura da IMA foram mantidos, como por ex.: quartzo (mineral); caulim e bentonita (são nomes de rochas e também de argilas). Por outro lado, é usual, especialmente por leigos e profissionais da indústria, chamar a rocha pelo nome do mineral. Um exemplo é o nome talco (mineral), que também é usado para designar a rocha rica no mineral talco; nesse caso, infelizmente, o nome talcito (que seria o correto) nunca foi usado. Ainda para esse caso, a melhor solução seria usar a expressão "rocha talcítica", que também não é utilizada. Obviamente, é errado trocar os nomes quando o nome da rocha deveria ser usado e é em-

*e-mail: acvcoelh@usp.br pregado o nome do mineral. Infelizmente, isso também ocorre com as argilas: o termo caulinita é usado em lugar de caulim; esmectita e montmorilonita em lugar de bentonita. Esses erros serão evitados no presente artigo.

Argila é uma rocha constituída essencialmente por um grupo de minerais que recebem o nome de argilominerais; tanto as diferentes argilas como também cada um das quatro dezenas de argilominerais têm nomes específicos.

Argilominerais são silicatos de $\mathrm{Al}, \mathrm{Fe}$ e $\mathrm{Mg}$ hidratados, com estruturas cristalinas em camadas (são filossilicatos), constituídos por folhas contínuas de tetraedros $\mathrm{SiO}_{4}$, ordenados de forma hexagonal, condensados com folhas octaédricas de hidróxidos de metais tri e divalentes; a maioria dos argilominerais, naturalmente, é constituída essencialmente por partículas (cristais) com algumas dimensões geralmente abaixo de $2 \mu \mathrm{m}$. Os argilominerais são muitas vezes chamados "silicatos em camadas" ("layer silicates") e "filossilicatos". Alguns argilominerais podem conter uma fração com dimensões na faixa de 1 a $100 \mathrm{~nm}$; essa faixa recebe o nome de nanométrica. Portanto, os termos argila e argilomineral referem-se a materiais encontrados na natureza. Existem cerca de 40 argilominerais; somente poucos são constituintes das Argilas Industriais e das Argilas Especiais, devido a possuírem algumas propriedades muito peculiares e/ou específicas que levam ao seu maior valor tecnológico. Devido às dimensões micro ou nanométricas, os microcristais da maioria dos argilominerais só podem ser visualizados por microscopia eletrônica de transmissão (MET); alguns podem também ser observados por microscopia eletrônica de varredura (MEV).

Supondo os microcristais de uma argila com a forma de cubos, todos iguais com 2,0 $\mu \mathrm{m}$ de lado (é uma hipótese simplificadora) e a densidade de $2,60 \mathrm{~g} / \mathrm{cm}^{3}$, a área específica $\mathrm{AE}\left(\mathrm{m}^{2} / \mathrm{g}\right)$, calculada pela Equação $A E=\frac{6}{l \times \rho}$, (onde $l$ é o lado do cubo, e $\rho$ sua densidade), é de $1,15 \mathrm{~m}^{2} / \mathrm{g}$. Assim, segundo Gregg ${ }^{3}$, as argilas são sólidos naturalmente ativos porque têm áreas específicas superiores a $1,0 \mathrm{~m}^{2} / \mathrm{g}$.

Argilas Industriais são um grupo de argilas, assim designadas pelo "U.S. Bureau of Mines", que são utilizadas em grande escala pelas indústrias de processamento químico; são elas: caulim; "ball clay" (argila plástica para Cerâmica Branca); argila refratária; bentonita; terra 
fuller; argila para fins de construção civil (Cerâmica Vermelha; Cimento); vermiculita; talco; pirofilita; amianto ou asbesto ${ }^{4}$.

\section{ARGILOMINERAIS: CLASSIFICAÇÃO}

Os diferentes argilominerais são classificados em grupos com base nas semelhanças em composição química e na estrutura cristalina. As estruturas cristalinas são classificadas em 2 tipos: estruturas 1:1 e estruturas 2:1. Nas estruturas 1:1, estão os grupos: da caulinita; das serpentinas; dos argilominerais ferríferos. Nas estruturas 2:1 estão os grupos: do talco-pirofilita; das micas; das esmectitas; das vermiculitas; das cloritas; da paligorsquita (atapulgita) - sepiolita. As quatro dezenas de argilominerais distribuem-se nesses grupos; apenas um pequeno número de argilominerais são componentes das Argilas Industriais: caulinita (caulim, "ball clay"; argila refratária; argila para construção civil); montmorilonita (bentonita, terra fuller); talco (talco); vermiculita (vermiculita) e amianto crisotila (amianto).

Segundo a conceituação da revista "Industrial Minerals"1 são os seguintes argilominerais que possuem os requisitos para serem constituintes das Argilas Especiais: raros comercialmente - hectorita (grupo das esmectitas) e sepiolita (grupo paligorsquita-sepiolita); de ocorrência restrita - bentonita branca (montmorilonita e hectorita); haloisita (grupo da caulinita) e paligorsquita (atapulgita) (grupo paligorsquita-sepiolita); montmorilonitas ativada por ácidos e as "organoclays" ou "organoclad clays" ou "organophilic clays"; as argilas organofílicas, em especial as montmorilonitas organofílicas, estas últimas são também atualmente chamadas "nanoargilas" (nanoclays). É importante assinalar que a maioria dos casos de aplicação no item montmorilonitas está baseada no argilomineral "montmorilonita propriamente dita" do grupo das esmectitas. Como esse número é apreciável, esse fato justifica um artigo especial sobre "argilas modificadas por tratamento químico".

Nesta revisão sobre argilas especiais procurar-se-á ampliar o conceito original, de forma a incluir outros exemplos de produtos comerciais especiais derivados do processamento de maior número de tipos de argilas que aqueles citados acima, buscando apresentar também exemplos brasileiros.

\section{ARGILAS ESPECIAIS COMERCIALMENTE RARAS}

São argilas das quais existem apenas um ou dois depósitos de dimensões que tornam rentável a comercialização das mesmas, em decorrência de suas propriedades tecnológicas valiosas.

\section{Hectorita, Saponita, Diquita}

O primeiro caso está relacionado com o argilomineral esmectítico "hectorita", cuja fórmula da cela unitária cristalina é:

$\left(\mathrm{Mg}_{5,33} \mathrm{Li}_{0,67}\right) \mathrm{Si}_{8} \mathrm{O}_{20}(\mathrm{OH})_{4} \rightarrow \mathrm{M}_{0,67}^{+} \quad$ onde $\mathrm{M}^{+}$é geralmente $\mathrm{Na}^{+}$

Uma argila constituída essencialmente por esse argilomineral esmectítico deveria ser chamada "argila esmectítica" ou então "bentonita", se tivesse propriedades tecnológicas semelhantes às da bentonita do Estado de Wyoming, USA. Entretanto, a prática comercial também chama a argila de "hectorita"; portanto, o primeiro caso de argila especial rara é a "hectorita". Os depósitos estão em Hector, Califórnia, USA, e no Amargosa Valley, Nevada, USA. A hectorita sódica tem propriedades reológicas no sistema [argila + água] superiores às da bentonita sódica de Wyoming, além da cor branca das dispersões e géis. É usada em aerossóis, colas e adesivos, látex de borracha, clarificação de cervejas e vinhos, esmaltes cerâmicos, cosméticos e produtos para toalete, produtos de limpeza doméstica, tin- tas de emulsão e para eletro-deposição, para revestimento de agregados e para fabricação de argilas organofílicas. Cerca de 2000 t de hectoritas organofílicas são produzidas nos EUA por ano ${ }^{1}$.

Outro argilomineral do grupo das esmectitas é a saponita, a qual tem propriedades semelhantes às da hectorita, porém com diferenças grandes na composição química estrutural. A fórmula da cela unitária da saponita é:

$\left(\mathrm{Mg}_{6}\right)\left(\mathrm{Si}_{7,33} \mathrm{Al}_{0,67}\right) \mathrm{O}_{20}(\mathrm{OH})_{4} \rightarrow \mathrm{M}_{0,67}^{+}$

A forma sódica tem cor branca e boas propriedades coloidais como gelificante; é muito usada para produtos farmacêuticos e de toalete. Nos EUA, a empresa R. T. Vanderbilt comercializa saponitaNa de Beatty, Nevada, com o nome de Veegum.

Um argilomineral raro, do grupo da caulinita, é a diquita; se existissem depósitos com valor comercial, seria excelente matériaprima para fabricação de materiais refratários sílico-aluminosos e aluminosos, devido às maiores dimensões de seus cristais comparados com aqueles da caulinita.

A Figura 1 mostra uma MET de cristais lamelares alongados de hectorita de Hector, Califórnia; a Figura 2 mostra uma MET de cristais lamelares alongados e placas com perfil irregular de saponita de Svardsjo, Suécia; a Figura 3 mostra uma MEV de cristais lamelares com perfil hexagonal de diquita de Ouray, Colorado, EUA. Os microscópios utilizados para obtenção das micrografias foram o microscópio de transmissão Philips CM200, operando a 200 kV e o microscópio de varredura JEOL modelo JSM840A, operando a $25 \mathrm{kV}$, ambos do Laboratório de Microscopia Eletrônica do Departamento de Física Geral (LME-DFG) do IF - USP.

Até o presente não há registro de ocorrência de hectorita, saponita e diquita no Brasil.

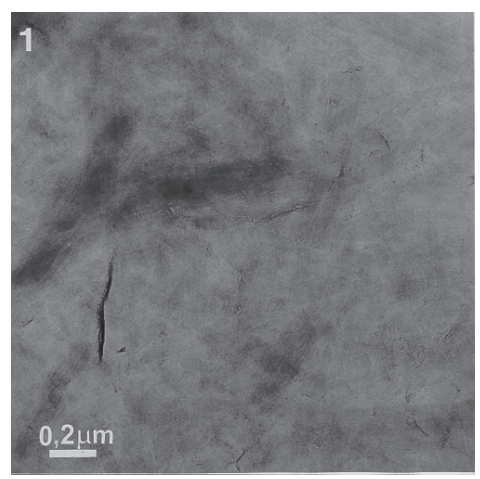

Figura 1. MET de cristais lamelares alongados de hectorita, de Hector, Califórnia, USA

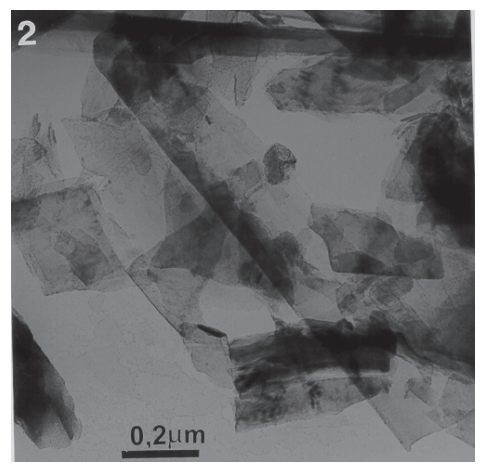

Figura 2. MET de cristais lamelares alongados e placas com perfil irregular de saponita de Svardsjo, Suécia 


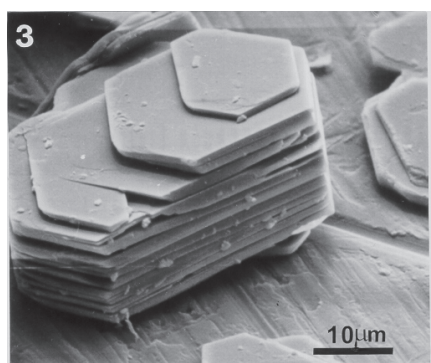

Figura 3. MEV de cristais lamelares com perfil hexagonal de diquita, Ouray, Colorado, USA

\section{Hectorita sintética ou Laponita}

Entre 1965 e 1970, as Indústrias Laporte desenvolveram e introduziram no mercado internacional uma hectorita sintética a partir de talco; o produto "Laponite B" é considerado idêntico estruturalmente e também em propriedades tecnológicas à hectorita-Na natural, além de ser livre de impurezas. As Laponitas são vendidas pela metade do preço da hectorita lavada e seca por nebulização.

\section{Sepiolita}

O caso seguinte é o argilomineral/argila "sepiolita". A maioria da produção vem da Espanha (cerca de 400.000 t/ano); existe uma pequena produção na Turquia (província de Anatólia) e nos EUA (Amargosa Valley, Nevada) ${ }^{1}$. A fórmula da cela unitária cristalina é

$\mathrm{Mg}_{18} \mathrm{Si}_{24} \mathrm{O}_{60}(\mathrm{OH})_{12} \cdot\left(\mathrm{OH}_{2}\right)_{8} \cdot 12 \mathrm{H}_{2} \mathrm{O}$

Curiosamente, sepiolita é um argilomineral de ocorrência rara e concentrada em muito poucas localidades, porém já vem sendo usado há alguns séculos, tanto em porcelana (figurinhas de "biscuit"), como na fabricação de cachimbos de "espuma-do-mar". Atualmente, as aplicações industriais são mais diversas e maiores, e se baseiam nas propriedades ab-adsortivas do argilomineral: agente clarificante e descorante de líquidos; auxiliar de filtração; abadsorvente industrial; suporte de catalisadores e de biocidas, além das suas excelentes propriedades reológicas em dispersões aquosas e em solventes orgânicos. Os microcristais de sepiolita podem ter áreas específicas "externas" de até $300 \mathrm{~m}^{2} / \mathrm{g}$ e áreas específicas "internas", devido a canais e poros, de até $400 \mathrm{~m}^{2} / \mathrm{g}$; a área específica total é das maiores dos materiais em pó. A argila sepiolita pode absorver 2,5 vezes seu peso em água, propriedade essa responsável pela grande plasticidade do sistema argila + água.

$\mathrm{Na}$ natureza, os microcristais de sepiolita ocorrem em feixes de agulhas alongadas e flexíveis que dispersam facilmente em água ou em outro solvente polar, produzindo um reticulado tridimensional que ocupa todo o líquido; em concentrações elevadas, há a formação de géis tixotrópicos. A variação de concentração provoca uma elevação de viscosidade da dispersão e, com isso, um aumento da capacidade de manter em suspensão partículas sólidas; essa propriedade faz a sepiolita ser muito utilizada em tintas e em fluidos de perfuração de poços de petróleo para grandes profundidades (devido à estabilidade térmica das dispersões) e em água salgada. Por outro lado, as fibras de sepiolita são muito flexíveis em água e não quebram com a agitação, fato esse que ocorre também com os microcristais alongados de paligorsquita (atapulgita). Além das aplicações mencionadas, sepiolita é utilizada em desodorantes do meio ambiente; como ab-adsorvente de dejetos de animais (em "cat litter", "banheiros de gatos", principalmente na Europa); em tintas de asfalto; em agentes anti-empedrantes; em filtros de cigarros; em platisóis e borrachas; em nutrição animal; em detergentes; em cosméticos; em produtos agrícolas, como por ex. na formulação de fertilizantes; com espessador de graxas; em papéis para cópia sem carbono. A produção espanhola é de 400.000 t/ano, de sepiolita proveniente da região de Madrid-Toledo ${ }^{1}$.

No Brasil já foram assinaladas pequenas ocorrências de sepiolita (caracterizada por DRX - difração de raios-X, e por MET) em Ponte Alta, MG; Jacuba, São José do Tocantins, GO e em Brumado, BA. A Figura 4 é uma MET de cristais fibrosos longos e flexíveis de sepiolita de Brumado, BA $^{5}$.

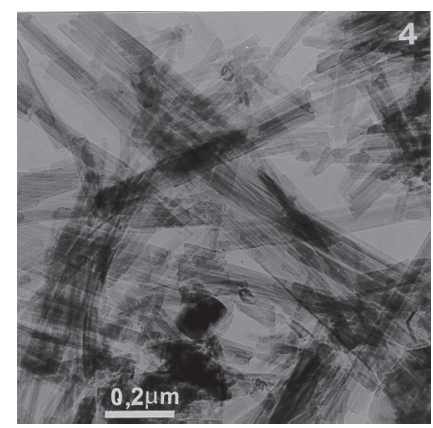

Figura 4. MET de cristais fibrosos longos e flexíveis de sepiolita de Brumado, Bahia

\section{Alofânio}

O caso seguinte é o argilomineral (chamado mineralóide por ser não-cristalino ou "amorfo" à DRX) "Alofânio". Não tem cela unitária cristalina. A fórmula de óxidos é:

$\left(\mathrm{SiO}_{2}\right)_{1,3} \mathrm{Al}_{2} \mathrm{O}_{3} \cdot 2,5 \mathrm{H}_{2} \mathrm{O}$

Localidades de onde é extraído: Freiberg, Alemanha; Devon, Inglaterra. Vem sendo utilizado como aditivo para placas de concreto com alta resistência ao choque e ao impacto a projéteis, para uso em carros de combate e armamentos. Não há registro de ocorrência no Brasil.

\section{Casos brasileiros}

São de nosso conhecimento dois casos brasileiros de argilas comercialmente raras, porém os depósitos já estão esgotados. São eles: antigorita de Castro, PR, e a caulinita especial de Piedade, SP.

Antigorita é o argilomineral magnesiano do grupo das serpentinas, cuja fórmula da cela unitária é:

$\mathrm{Mg}_{60} \mathrm{Si}_{4} \mathrm{O}_{10}(\mathrm{OH})_{8}$

A forma usual do argilomineral encontrada na natureza é como uma rocha maciça, de cor verde-clara. A antigorita de Castro ocorre próxima a depósitos de talco, tem cor muito branca (alvura: 9092) e ocorre como uma argila, isto é, como um pó constituído por microcristais lamelares ${ }^{6}$.

Durante uma dezena de anos, até o esgotamento da ocorrência, a antigorita foi utilizada como talco em cosméticos, em Cerâmica Branca e como carga para plásticos. A Figura 5 é uma MET de cristais lamelares alongados e placas com perfil irregular de antigorita de Castro, $\mathrm{PR}^{6}$.

A caulinita especial de Piedade tem cristais com morfologia tubular alongada e características na DRX comuns à caulinita e ao argilomineral do mesmo grupo haloisita- $4 \mathrm{H}_{2} \mathrm{O}$. Foi utilizada em 


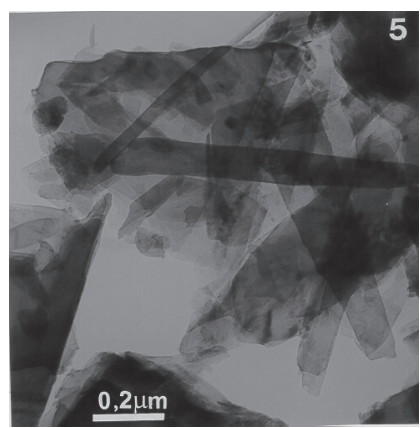

Figura 5. MET de cristais lamelares alongados e placas com perfil irregular de antigorita de Castro, Paraná

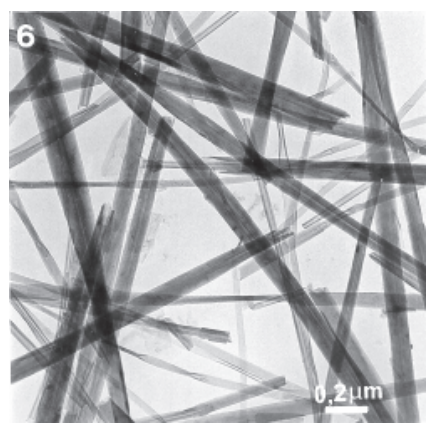

Figura 6. MET de cristais tubulares muito longos de caulinita-10Å especial de Piedade, São Paulo

Cerâmica Branca e como carga para biocidas até o esgotamento da ocorrência. A Figura 6 é uma MET de cristais tubulares muito longos de caulinita-10 A especial de Piedade, $\mathrm{SP}^{7}$.

\section{ARGILAS ESPECIAIS DE ÁREAS RESTRITAS}

Este grupo compreende três tipos de argilas especiais: bentonita branca, "haloisita"; "atapulgita (paligorsquita)". Na realidade, os dois últimos nomes são de argilominerais usados também para argilas.

\section{Bentonita Branca}

Os depósitos são raros, devido às condições peculiares de formação geológica (ausência de matéria orgânica e de rochas contendo ferro e outros metais com cátions coloridos durante a decomposição de cinzas vulcânicas ricas em sílica). São constituídas essencialmente por montmorilonita-Na sem ferro estrutural e sílica coloidal; hectorita-Na e saponita-Na podem ser também os constituintes de bentonitas brancas comerciais.

Existem depósitos explorados comercialmente apenas na Califórnia e em Nevada (Death Valley e Amargosa Valley) e Texas (Gonzáles), USA; na Turquia (Balikesia) e Grécia (ilha de Kimilos). Os Estados Unidos são os maiores produtores: 225.000 t/ano. As bentonitas brancas lavadas são vendidas por US\$4.000,00/t. Das 200.000 t produzidas na Califórnia e Nevada, cerca de 55\% são usadas para gelificação em cosméticos, produtos de toalete e produtos para limpeza doméstica; cerca de $35 \%$ são usados como agentes estabilizantes de suspensões desses mesmos produtos e $8 \%$ são usados como agente plastificante em Cerâmica Elétrica. A bentonita branca produzida no Texas é utilizada industrialmente: esmaltes e vidrados cerâmicos; agente plastificante para Cerâmica Branca, Cerâmica Elétrica, Cerâmica Técnica e Refratários Plásticos. Na Província de San Juan, região andina da Argentina, existem vários depósitos de bentonita branca, com teores de ferro excepcionalmente baixos ${ }^{8}$. O depósito da área denominada Hipo passou a ser industrializado a partir de 2001, sendo iniciada a exportação em fins desse mesmo ano.

Um detalhe interessante: se a bentonita branca tiver de satisfazer as especificações para uso farmacêutico e cosmético, a suspensão aquosa é seca por nebulização para ficar adequada para o controle microbiológico e produzir um pó de fácil escoamento ("free flowing").

No Brasil, na década de 80, houve extração de bentonita branca dos pegmatitos do Rio Grande do Norte e Paraíba. Atualmente há ocorrência pequena de bentonita branca nos depósitos de bentonita de Boa Vista, Campina Grande, PB; é constituída por mistura de montmorilonita e paligorsquita. Está sendo extraída e utilizada em Cerâmica Branca, como agente suspensor de esmaltes cerâmicos.

\section{Haloisita}

É o nome de um dos argilominerais do grupo da caulinita. Existe na forma denominada haloisita- $7 \AA$, que tem a mesma fórmula da caulinita e a forma, dita hidratada, de haloisita- $10 \AA$, com fórmula de óxidos $\mathrm{Al}_{2} \mathrm{O}_{3} \cdot 2 \mathrm{SiO}_{2} \cdot 4 \mathrm{H}_{2} \mathrm{O}$; a forma $10 \AA$ passa a $7 \AA$ com o aquecimento a $50{ }^{\circ} \mathrm{C}$. Os depósitos comerciais de haloisita-7 $\AA$ "puros", isto é, sem mistura com caulinita, são raros. Atualmente, o maior produtor/exportador é a Nova Zelândia (Matauni Bay); ocorre também no Japão, Coréia do Sul, USA, França, Marrocos e Filipinas. Com maior frequiência, os microcristais de haloisita-7 $\AA$ são tubos $\operatorname{ocos}^{9}$.

Haloisita, ou melhor falando o caulim essencialmente haloisítico, ocupa um nicho de produção de porcelana de alta qualidade (Japão e França), onde alvura e translucidez elevadas são características desejadas e valiosas. Nas décadas de 70 e 80, catalisadores baseados em haloisita foram utilizados para craqueamento de petróleo.

A Indústria de Cerâmica Branca no Brasil, desde a década de 40, vem utilizando caulins residuais do Sudeste e do Sul do Brasil, constituídos por misturas de proporções variáveis de haloisita-7 e caulinita ${ }^{9}$. A Indústria de Papel no Brasil também sempre usou esses caulins como carga para papel "sulfite". Esses mesmos caulins, calcinados entre 600 e $1000{ }^{\circ} \mathrm{C}$, vêm sendo usados como cargas para plásticos e borrachas. A haloisita dos caulins brasileiros geralmente contém pequenos teores de ferro, o que lhe confere cor rosada; a calcinação costuma branquear esses caulins rosados. A Figura 7 é a MET de um caulim essencialmente haloisítico com cristais tubulares de Mar de Espanha, $\mathrm{MG}^{9}$.

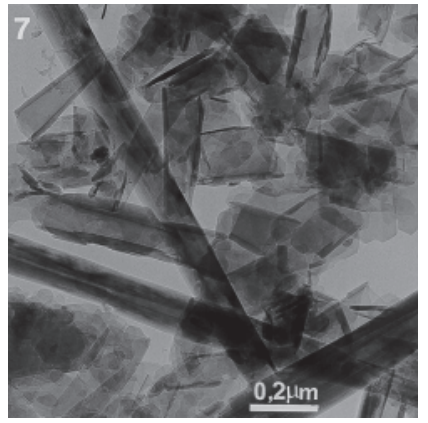

Figura 7. MET de caulim haloisítico com cristais tubulares de Mar de Espanha, Minas Gerais

\section{Haloisita esférica}

A haloisita-10 A pode ocorrer como microcristais lamelares, tubulares e esféricos; a forma esférica é muito freqüente, principal- 


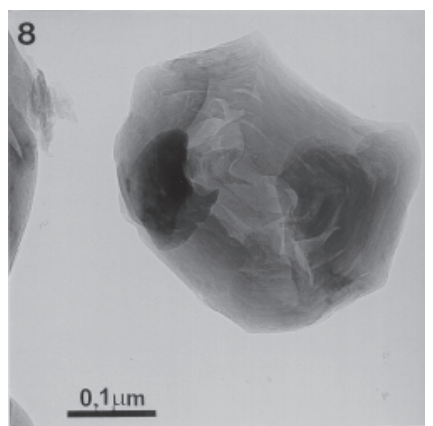

Figura 8. MET de cristal esférico em camadas de haloisita-10 A de Ponte Nova, São Paulo

mente na decomposição de rochas vulcânicas; é muito comum no Japão onde é utilizada em Cerâmica Branca e Papel e nos EUA. No Brasil é rara, sendo encontrada com caulim haloisíticos do sudeste Brasileiro. Foi também encontrada uma ocorrência em Ponte Nova, próxima de Mogi das Cruzes, $\mathrm{SP}^{10}$. A Figura 8 é a MET de um cristal esférico em camadas de haloisita- $10 \AA$ de uma haloisita dessa localidade.

\section{Atapulgita}

O nome correto do argilomineral é paligorsquita ("palygorskite"), bem como da argila. De todas as argilas especiais, "atapulgita" é a argila de maior produção no mundo ocidental: cerca de 1 milhão de t por ano, das quais 93\% provêm dos USA (Flórida e Geórgia) e o restante é proveniente do Senegal, da Espanha, Austrália e África do $\mathrm{Sul}^{1}$. Como esse é o nome comercialmente utilizado, ele será empregado neste trabalho. "Atapulgita" pertence ao grupo paligorsquitasepiolita. A fórmula da cela unitária cristalina é a seguinte:

$\mathrm{Mg}_{10} \mathrm{Si}_{16} \mathrm{O}_{40}(\mathrm{OH})_{4} \cdot\left(\mathrm{OH}_{2}\right)_{8} \cdot 8 \mathrm{H}_{2} \mathrm{O}$

onde, tal como na sepiolita, $\mathrm{OH}_{2}$ representa água estrutural e $\mathrm{H}_{2} \mathrm{O}$ representa água preenchendo os microcanais fibrosos do argilomineral. Os cristais fibrosos de atapulgita são mais rígidos e, portanto, menos flexíveis comparados com aqueles de sepiolitas. Nos Estados da Geórgia e da Flórida, USA, muitas das ocorrências de atapulgita são associadas a camadas de montmorilonita propriamente dita. Assim, existem dois tipos de atapulgita para fins comerciais: atapulgita gelificante e atapulgita não-gelificante ("non-gelling"). A primeira contém apenas atapulgita e forma um gel em água e em soluções salinas, enquanto a segunda é uma mistura natural de atapulgita e montmorilonita, que precipita quando colocada em água. Os dois tipos são igualmente usados industrialmente como absorvente de óleos (na limpeza de assoalhos industriais, em especial), suportes primários para biocidas, para banheiro de gatos ("pet" ou "cat litter"); para cobrir o chão de vagões transportadores de gado, e para uso como absorvente de óleos e gorduras para rações animais. O tipo gelificante tem a mais cinco usos específicos: agente tixotrópico em perfuração de poços de petróleo em regiões salinas ou com águas salinas, porque o fluido viscoso não flocula pela ação dos sais dissolvidos na água; manuseio e distribuição de fertilizantes líquidos (ex.: amônia líquida) que preenchem os canais estruturais dos cristais e para substituir amianto crisotila em materiais de revestimento, vedação e pavimentação à base de asfalto; adsorvente e desodorante das frações do petróleo, especialmente querosene para motores a jato, e adsorventes para fins farmacêuticos.

As atapulgitas gelificantes podem ter suas propriedades adsortivas específicas e viscosidades melhoradas pela desidratação a cerca de 500/550 ${ }^{\circ} \mathrm{C}$ (é o produto LVM, "low volatile material"; seco a $110^{\circ} \mathrm{C}$ é RVM, "regular volatile material") ou por extrusão em marombas usadas na Indústria Cerâmica. As atapulgitas não-gelificantes são vendidas por cerca de US\$ 250 por t, e as gelificantes por cerca de US\$ 450 por $\mathrm{t}^{1}$.

No Brasil, até a poucos anos, somente pequenas ocorrências, sem valor comercial, haviam sido assinaladas ${ }^{5}$. A bentonita branca de Boa Vista, Campina Grande, PB, contém atapulgita juntamente com o argilomineral esmectítico ${ }^{11}$. Recentemente foi descoberto um depósito em Nova Guadalupe, PI, o qual está sendo explorado e o produto é comercializado em São Paulo ${ }^{12}$. A Figura 9 é uma MET de cristais alongados e rígidos de paligorsquita (atapulgita) de Guadalupe, PI.

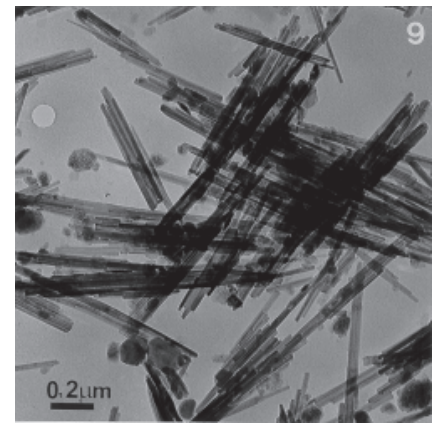

Figura 9. MET de cristais alongados e rígidos de paligorsquitas (atapulgita) de Guadalupe, Piauí

\section{“Cat litter"}

A tradução mais aproximada da expressão norte-americana "cat litter" é "granulado sanitário para gatos"; existem outras formas da mesma expressão: "pet litter"; "pet absorbent"; "pet waste"; "animal pad"; "animal absorbent". Em francês é "argile pour litières pour animaux familiers". Entretanto, tudo isso se aplica somente aos gatos, uma vez que cachorros não têm esse comportamento, geralmente necessitando sair à rua para fazer suas necessidades. Este é um exemplo, não de uma argila especial, mas de um uso especial e curioso de uma argila industrial, a bentonita-Na, que é hoje economicamente muito importante, suplantando todos os outros empregos industriais da bentonita nos EUA e que está sendo crescente na Europa.

Todo aquele que tem ou teve um gato sabe que, se o gato não foi treinado para fazer a toalete fora de casa ou apartamento, é necessário ter uma bandeja especial para suas necessidades. Para um dono de gato morando em apartamento, a bandeja para toalete de gato é simplesmente indispensável. Obviamente o material de revestimento da bandeja deve ser de limpeza fácil e higiênica. Por outro lado, se a população de gatos domésticos aumentar, como de fato aumentou, a demanda por mais e melhores materiais absorventes para toalete de gatos também aumentou. O mercado do "cat litter" é muito grande e continua aumentando; exemplificando: em 1992 era de 1 milhão de t por ano (70\% sepiolita; $30 \%$ montmorilonita) na Europa, onde havia 4 milhões de gatos na Alemanha e 14 milhões de gatos na França; na Inglaterra, um terço dos donos de gatos comprava $200 \mathrm{~kg}$ de "cat litter" por ano; nesse ano havia 60 milhões de gatos nos EUA. Em 1999, a Europa produziu 1,2 milhões de t e os EUA 2,0 milhões de t de "cat litter"13.

Um certo número de requisitos é necessário para a argila de preenchimento da bandeja para toalete dos gatos: volume elevado de líquido absorvido; densidade aparente e dimensões grandes das partículas ou grãos; não levantar poeira; controle de cheiros e odores e, principalmente, ser aceita pelo gato. A aceitação é necessária, obviamente, para evitar mudanças de comportamento que pos- 
sam alterar os hábitos de higiene dos gatos. Assim, argila deve possuir elevado poder de absorção, não somente para absorver todo o volume de urina como também para desidratar as fezes; em conseqüência, os odores são reduzidos e o crescimento bacteriano inibido temporariamente. Fatores como métodos para limpeza ou disposição, embalagens e duração também devem ser levados em conta. Existe uma Norma Técnica Francesa (NFV 19-002; Février, 1993) para medir o poder absorvente ou capacidade de retenção de água do "cat litter". Ele deve funcionar como um polímero superabsorvente funciona para seres humanos.

A distribuição dos tamanhos das partículas ou grãos é também muito importante e está, usualmente, na faixa de $1 / 6 \mathrm{~mm}$. O requisito é que eles não devem ficar presos nas patas ou grudados nos pelos do gato e devem ter formato arredondado, para evitar ferimentos nas patas quando o gato anda sobre o "cat litter". As partículas ou grãos devem ser resistentes à abrasão, para evitar a formação de poeira.

Em 1985, duas linhas de produção principais de "cat litter" passaram a existir, cujos nomes são: "Traditional litters" ou "Nonclumping pet litters"; "Clumping cat litter" ou "Scoopable cat litter"14. "Traditional litters" não aglomeram quando molhados por urina. Muito embora esses "litters" absorvam líquidos, a urina não fica na bandeja na forma de grumos ("clumps"). Os "Traditional litters" podem ser produzidos por diversas matérias-primas, como paligorsquitas (atapulgita), bentonitas-Ca, zeólitas e diatomito. O produto "Traditional Litter" existia no mercado há 40 anos nos EUA.

"Scoopable Litter" significa literalmente "argila suja que pode ser retirada com uma colher do tipo de colher de sorveteiro"; "Clumpable Litter" significa "argila suja em grumos".

"Scoopable Litter" é definido como uma material granular que aglomera quando molhado, para formar concentrações isoladas de sujeira ("dross") ou rejeito ("waste") animal sobre a superfície da argila ("litters"). Esses "litters" têm características tais que servem para isolar os dejetos do gato do "litter" não-molhado pela urina ou fezes, localizando e isolando a sujeira a ser retirada ("scooped"). Como resultado, são produzidas concentrações facilmente visíveis, chamadas grumos ("clumps") (no Brasil: "montinhos"). O restante do "cat litter", fica inalterado e continua pronto para ser usado. Bentonitas$\mathrm{Na}$ servem como matéria-prima usual para "scoopable litters", mas outras argilas (atapulgita) podem ser adicionadas para facilitar a aglomeração; os grânulos têm 1-2 mm de diâmetro.

O que é espantoso: segundo o U.S. Bureau of Mines, em $2002^{15}$, a produção de bentonita nos EUA foi de 3,97 Mt no valor de US\$ 180 milhões. Usos: "pet litter" (899.000 t); Fluido para Perfuração (762.000 t); Fundição (762.000); Pelotização (536.000). Quantos seriam hoje os milhões de gatos dos EUA?

\section{Rações animais e de aves ("Animal and poultry feed")}

Uma observação inesperada, que também levou a um aumento do consumo, foi a de que a bentonita-Na, muito usada como ligante para rações de animais e de aves, tem a propriedade de aumentar a capacidade de extrair mais nutrientes dos alimentos contidos nas rações. No caso das aves, a bentonita auxilia também a aumentar tanto o tamanho, quanto a dureza da casca dos ovos ${ }^{16}$.

\section{"Clay Mineral Standards", "Source Clays" e "Special Clays"}

Em 1949, o Comitê de Pesquisa do American Petroleum Institute contratou o Prof. P. F. Kerr da Columbia University, USA, para executar o projeto API n 49 - "Clay Mineral Standards" (Padrões de Argilominerais). O objetivo do projeto era caracterizar mineralogicamente os argilominerais das argilas industrialmente importantes dos EUA e de alguns países europeus e estabelecer uma coleção de amos- tras-padrão de argilominerais para o API e para o museu de Mineralogia da Columbia University. O projeto envolveu caulins cauliníticos e haloisíticos norte-americanos, ingleses, franceses e alemães; bentonitas sódicas e cálcicas norte-americanas e inglesas; ilita, atapulgita e pirofilita norteamericanas e diquita inglesa.

As localidades estudadas receberam o nome de "Reference Clay Minerals Sources" e os argilominerais das argilas estudadas foram chamados "Reference Clay Minerals" do "API Research Project 49". Os resultados da pesquisa foram publicados em monografias separadas, cada uma contendo o conjunto de argilas caracterizado por um método experimental. Os títulos dessas monografias são: Glossário; "Reference Clays Localities - USA", contendo geologia e fotografias dos depósitos; "Reference Clay Localities-Europe", o mesmo conteúdo; "Differential Thermal Analysis of Reference Clay Minerals Specimens", contendo todas as curvas de ATD; "Microscopic Examination of the Reference Clay Minerals Specimens", contendo esquemas das micrografias ópticas das impurezas das argilas; "Electron Micrographs of Reference Clay Minerals", contendo METs de todas as argilas; "Analytical Data on Reference Clay Minerals", contendo Difração de raios-X; Análises Químicas; Dados de pH; ATD e propriedades ópticas das argilas européias; análise espectrográfica de elementos; capacidade de troca de cátions; susceptibilidade magnética; distribuição granulométrica e ensaios de coloração; "Infrared Spectra of Reference Clay Minerals", contendo todas as curvas dos espectros no infra-vermelho. As 7 monografias foram encadernadas e publicadas como um livro com o título "Reference Clay Minerals API Project 49", o qual foi distribuído pelo American Petroleum Institute $^{17}$. Ainda hoje, constitui obra de referência, especialmente comparativa para finalidades sobre um grupo importante de argilas industriais. As amostras originais coletadas pelo Prof. Kerr infelizmente já acabaram. As curvas de DRX das "Reference Clay Minerals" obtidas em equipamentos modernos foram publicadas por Molloy e Kern ${ }^{18}$. As micrografias eletrônicas de varredura das mesmas amostras foram publicadas por Borst e Keller ${ }^{19}$.

"Source Clay Repository" da Clay Minerals Society, USA - Em 1970 a necessidade de fontes de amostras homogêneas de argilas havia se tornado clara para os pesquisadores norte-americanos da área. Os depósitos na natureza variam tanto que dados obtidos por diferentes pesquisadores, trabalhando com a mesma exposição do depósito, não podem ser comparados com segurança. Assim, a Clay Minerals Society estabeleceu o "Source Clay Project". Atualmente o "Source Clay Repository" da Sociedade oferece dois "tipos" de argilas que foram chamados "Source Clays" e "Special Clays".

As "Source Clays" provêm de lotes grandes e razoavelmente homogeneizados de argilas bem conhecidas, principalmente pelo uso industrial. Cada lote original era de uma tonelada; ficavam no Departament of Geological Sciences da Universidade de Missouri. As primeiras "Source Clays" foram: caulins da Geórgia com poucos e muitos defeitos estruturais (cristalinidades baixa e alta); bentonita$\mathrm{Na}$, Wyoming, bentonita-Ca branca, Texas; Laponita; Nontronita, Washington e paligorsquita (atapulgita), Geórgia. Assim, ao longo dos anos, os dados obtidos com essas amostras de referências podem ser comparados de forma confiável. As amostram foram secas em temperatura baixa $\left(30-50{ }^{\circ} \mathrm{C}\right)$ e passadas em moinho Raymond.

A Clay Minerals Society organizou um número especial de sua revista Clays and Clay Minerals ${ }^{20}$, cujos artigos trataram de propriedades das "Sources Clays". Foram estudadas três caulinitas, paligorsquita, duas montmorilonitas-Ca e montmorilonita-Na. Os artigos são intitulados "Baseline Studies of the Clay Minerals Society Source Clays", e se dividem em: Introdução; Origem Geológica; Análise Química dos Elementos com Maiores Teores; Determinação da Carga da Camada 2:1 e Características dos Minerais contendo Camadas 2:1; 
Análise por Difração de Raios-X pelo Método do Pó; Métodos no Infravermelho; Análise Térmica; Medidas da Capacidade de Troca de Cátions pelo método do Eletrodo de Amônia; Fenômenos Coloidais e de Superfície. Como pode ser concluído, o número de amostras é menor que o do Projeto API n ${ }^{\circ} 49$, mas os ensaios são basicamente os mesmos e com vários ensaios novos; segundo recomendação da CMS, a referência 21 completa os dados sobre as "Sources Clays".

As "Special Clays" são raras, mas de grande interesse teórico. Não são homogeneizadas, nem beneficiadas. As "Special Clays" constantes do último catálogo são: ripidolita (clorita); rectorita; laponita; hectorita sintética; montmorilonita de Otay, Califórnia; esmectita ferrífera, Washington; montmorilonita de Cheto, Arizona; vermiculita, Texas; ilita, Montana e Wiscosin; nontronita, Austrália e Alemanha; corrensita, Washington; saponita, Califórnia; sepiolita, Espanha e Nevada; beidelita, Califórnia e Idaho.

Como pode ser visto, há muitas coincidências com as Argilas Especiais descritas no início desse artigo. A "Source Clay Repository" fornece todas as referências publicadas a cada amostra de "Source" ou "Special Clay". As referências cuidam da caracterização original das amostras atuais do "Repository".

\section{CONCLUSÃO}

$\mathrm{O}$ artigo procurou mostrar como o maior e melhor conhecimento das propriedades estruturais de um grupo de argilominerais constituintes, tanto de argilas raras como de argilas que já possuem vários usos industriais e são consumidas em grandes quantidades, pode ser aplicado para ampliar e aperfeiçoar o leque de aplicações de argilas, a ponto de ser criado o grupo de "Argilas Especiais" ao lado das tradicionais "Argilas Industriais".

\section{AGRADECIMENTOS}

À S. P. Toledo pela organização das figuras.

\section{REFERÊNCIAS}

1. Clarke, G. M.; Industrial Minerals 1985, September, 25.

2. Nickel, E. H.; Can. Mineral. 1995, 33, 689.

3. Gregg, S. J. Em Surface Phenomena in Chemistry and Biology; Danielli, U. F.; Pankhurst, K. G. A.; Riddiford, A. C., eds.; Pergamon: Londres, 1958.

4. Souza Santos, P. Em Proceed. 12th Intl. Clay Conf.; Dominguez, E.A.; Cravero, F., eds.; Elsevier, Amsterdam, 2003, p. 323-330.

5. Souza Santos, P.; Souza Santos, H.; Cerâmica 1984, 30, 319.

6. Brindley, G. W.; Souza Santos, P.; Clays Clay Miner. 1971, 19, 187.

7. Brindley, G. W.; Souza Santos, H.; Souza Santos, P.; Am. Mineral 1965, 50,619 .

8. Cravero, F.; Keith, K. S.; Murray, H. H.; Toth, T. Em Proceed. 11th Intl. Clay Conf.; Kodama, H., ed.; Elsevier: Geological Survey of Canada, Ottawa, 1997, p. 65-70; Allo, W. A.; Murray, H. H.; Appl. Clay Sci. 2004, 25,237

9. Campos, T. W.; Souza Santos, H.; Cerâmica 1986, 32, 355.

10. Souza Santos, P.; Souza Santos, H.; Resumos do $19^{\circ}$ Congresso da Sociedade Brasileira de Microscopia Eletrônica e Microanálise, Rio de Janeiro, Brasil, 2002.

11. Baraúna, O. S.; Araújo, A. P. R.; Souza Santos, H.; Souza Santos, P.; Cerâmica 1986, 32, 339.

12. Luz, A. B.; Almeida, S. L. M.; Ramos, L. T. S.; Boletim de Tecnologia Mineral $n^{\circ}$ 42; Centro de Tecnologia Mineral -CETEM/MME, Brasília, 1988.

13. Virta, R. L.; Arguelles, M.; Mineral Industry Surveys - Clay and Shale 1999, U.S. Geological Survey: Reston, 1999; Landis, C.; Gaylord, B.; Industrial Minerals 1999, August, 45.

14. Santarén, J.; Industrial Minerals 1993, January, 38.

15. Virta, R. L.; Mineral Industry Surveys - Clay and Shale 2002, U.S. Geological Survey: Reston, 2002.

16. O'Driscoll, M.; Industrial Minerals 1988, July, 43

17. Kerr, P. F.; Reference Clay Minerals - API Research Project 49, Columbia University: Nova York, 1951.

18. Molloy, M. W.; Kern, P. F.; Am. Mineral. 1961, 48, 583.

19. Borst, R. L.; Keller, W. L. Em Proceed. $3^{\text {rd }}$ Intl. Clay Conf; L. Heller, ed.; Israel University Press: Jerusalem, 1969, p. 871-901.

20. Constanzo, P. M.; Guggenhein, S.; Clays Clay Miner. 2001, 49, 371.

21. Van Olphen, H.; Fripiat, J. J.; Data Handbook for Clay Minerals and Other Non-Metallic Minerals, Pergamon Press: Oxford, 1979. 